\title{
Implementasi Nilai-Nilai Kearifan Lokal Catur paramitha dalam Pembelajaran dengan Model Discovery Learning Berpengaruh Positif Terhadap Kompetensi Pengetahuan IPS
}

\author{
Ni Komang Micka Pranintya Dewi ${ }^{1 *}$, I Wayan Sujana ${ }^{2}$ (D) \\ ${ }^{12}$ Prodi Pendidikan Guru Sekolah Dasar, Universitas Pendidikan Ganesha, Singaraja, Indonesia \\ *Corresponding author: komang.micka.pranintya@undiksha.ac.id
}

\begin{abstract}
Abstrak
Pada pembelajaran IPS, siswa masih menggunakan kemampuan mengingat daripada memahami konsep suatu materi serta kurangnya dalam memiliki etika yang baik dalam pembelajaran. Penelitian ini bertujuan untuk menemukan pengaruh model discovery learning berbasis kearifan lokal catur paramitha terhadap kompetensi pengetahuan IPS siswa kelas V di SD. Jenis penelitian ini yaitu penelitian eksperimen semu dengan rancangan Non-equivalent Control Group Design. Jumlah populasi pada penelitian ini adalah 259 orang. Penentuan sampel menggunakan teknik cluster random sampling. Data yang di peroleh dinormaliasasikan dengan gain skor kemudian dianalisis menggunakan analisis statistik inferensial uji t. Diperoleh hasil analisis data yaitu thitung $=3,065>\mathrm{t}$ tabel $=2,000$ untuk taraf signifikansi $5 \%$ dan $\mathrm{dk}=66$. Berdasarkan kriteria pengujian, Ho di tolak dan Ha diterima. Rata-rata gain skor ternormalisasi kompetensi pengetahuan IPS pada kelompok yang dibelajarkan dengan model discovery learning berbasis kearifan lokal catur paramitha adalah 0,517. Sedangkan pada kelompok yang dibelajarkan dengan pembelajaran konvensional adalah 0,383. Hasil penelitian ini dapat dijadikan alternatif bagi guru dalam pembelajaran IPS agar kompetensi pengetahuan IPS siswa sesuai dengan yang diharapkan. Model discovery learning berbasis kearifan lokal catur paramitha dapat diterapkan oleh guru karena sudah terbukti dapat mempengaruhi hasil kompetensi pengetahuan IPS siswa menjadi lebih baik. Berdasarkan hasil tersebut dapat disimpulkan bahwa terdapat pengaruh model discovery learning berbasis kearifan lokal catur paramitha terhadap kompetensi pengetahuan IPS siswa kelas V di Sekolah Dasar.
\end{abstract}

Keywords: Discovery Learning, Catur paramitha

\section{Abstract}

In social science, students still use the ability to remember, rather than understand the concept and did not have enough ethic in learning. This research aims to find the effect of discovery learning models based on Catur paramitha on social science of fifth grade students in elementary school. This type of research is quasi-experimental research with Nonequivalent Control Group Design. The population in this research was 259 people. Determination of the sample using cluster random sampling techniques. The data obtain were normalized by the gain score then analyzed using inferential statistical analysis of the t test. Obtained data analysis results are thitung $=3.065>t$ table $=2,000$ for a significance level of $5 \%$ and $d k=66$. Based on testing criteria, $H_{0}$ is rejected and $H_{a}$ is accepted. The average score gain normalized in the group learned by discovery learning model based on Catur paramitha is 0.517. Meanwhile, the group learned with conventional learning is 0.383. The results of this study can be uses as an alternative for teachers in learning, so that student's knowledge competencies in social science are as expected. Discovery learning model based on Catur paramitha, can be apply by the teacher, because it has been proven to be able to influence the results of student's knowledge competence in social science for the better. Based on these results, it can be concluded that, there is an influence of the discovery learning model based on Catur paramitha in the competence of social science knowledge of fifth grade students in elementary schools.

Keywords: Discovery Learning, Catur paramitha

\section{Pendahuluan}

Dalam era globalisasi, pendidikan mempunyai peranan penting untuk kemajuan umat manusia. Pendidikan tersebut dapat ditanamkan mulai dari usia dini. Menurut Sudhita (2019) pendidikan merupakan suatu kegiatan belajar untuk mempersiapkan peserta didik dalam peranannya dimasa yang akan datang. Pendidikan semestinya dapat membentuk karakter siswa agar pengetahuan yang dimilikinya tidak menyebabkan kerugian individu lain (Putra, 2020). Hal ini disebabkan karena pendidikan memberi bekal berupa pengetahuan yang dapat membentuk kepibadian seseorang (Rahmayani et al., 2019). Saat ini pendidikan di Indonesia

History:
Received : 4 Maret 2020
Revised : 23 Juni 2020
Accepted : 20 Agutus 2020
Published : 25 September 2020


menggunakan kurikulum 2013. Kurikulum 2013 menuntut siswa untuk berperan aktif seperti mencari, mengolah, mengkontruksi serta menerapkan pengetahuan. Inovasi-inovasi dalam mengajar sangat diperlukan dalam melakukan proses pembelajaran.

Pada suatu pembelajaran, setiap instansi pendidikan melakukan perencanaan, pelaksanaan proses dan penilaian proses pembelajaran untuk meningkatkan efesiensi ketercapaian kompetensi lulusan, khususnya dalam kompetensi pengetahuan IPS. Kompetensi pengetahuan IPS merupakan suatu ilmu pengetahuan yang lebih banyak membahas tentang kehidupan sosial. Mata Pelajaran IPS pada jenjang SD/MI mengandung materi Sejarah, Sosiologi, Ekonomi dan Geografi (Herijanto, 2012). Gunawan dalam (Meldina et al., 2020) menyatakan bahwa pembelajaran IPS memiliki tujuan sebagai berikut. 1) mengenal kan konsep yang berhubungan dengan kehidupan dan lingkngan, 2) mempunyai kemampuan awal untuk memecahkan masalah dalam kehidupan sosial. 3) mempunyai kesadaran dalam berkomitmen dalam nilai-nilai sosial dan etika. 4) serta mempunyai kemampuan berkomunikasi, bekerjasama dan berkompetensi dalam masyarakat yang majemuk. Sedangkan tujuan IPS yang dikemukakan oleh (Rahmad, 2016) yaitu untuk memajukan pontensi yang dimiliki siswa terhadap permasalahan yang terjadi di kehidupan sosialnya agar mampu dalam meyelesaikannya dengan baik. Pembelajaran IPS tidak hanya menuntut siswa untuk memahami apa yang telah dipelajari, tetapi juga harus mampu memberikan contoh-contoh sosial yang nyata di lingkungan masyarakat seputar materi yang disampaikan (Rosidah, 2016). Dari penjelasan yang dipaparkan, tampaknya diperlukan suatu pembelajaran yang dapat membantu mencapai tujuan tersebut. Penggunaan model, metode dan strategi pembelajaran dalam kemampuan dan keterampilan guru saat pembelajaran perlu ditingkatkan agar pembelajaran IPS dapat mewujudkan kemampuan dan sikap siswa untuk menjadi warga negara yang baik. fenomena yang terjadi di lingkungannya.

Masih rendahnya kompetensi pengetahuan IPS disebabkan oleh kebanyakan siswa masih menggunakan kemampuan mengingat daripada memahami konsep suatu materi. Selama ini, masih terdapat siswa yang kurang memiliki minat belajar terhadap mata pelajaran Ilmu Pengetahuan Sosial (IPS). Hal ini didasari oleh asumsi dalam memilih model dalam pembelajaran. Model pembelajaran yang penerapannya berpusat pada guru masih sering dilakukan. Pembelajaran konvensional adalah suatu pembelajaran yang penerapannya masih berorientasi pada guru (Widani et al., 2019). Model konvensional ini biasanya menggunakan pembelajaran yang ditandai dengan ceramah kemudian pemberian tugas serta latihan (Drs. I Wayan Sujana, 2017). Kondisi pembelajaran ini dapat menyebabkan siswa menjadi kurang aktif dan situasi pembelajaran menjadi kurang kondusif yang justru membuat siswa melakukan aktifitas yang tidak bermanfaat. Hal ini sejalan dengan pendapat Aif dan Rijanto dalam (Kristin, 2018) Apabila pada sustu kelas dalam proses pembelajarannya hanya bersifat mengingat suatu materi tanpa perlu memahami konsep materi tersebut maka siswa mengalami kesulitan ketika diberi soal-soal penalaran. Seperti yang diketahui bahwa mata pelajaran IPS erat kaitannya dengan hubungan sosial. Diperlukan suatu model pembelajaran IPS yang diimbangi dengan ajaran dalam bersikap sosial siswa agar mejadi warga negara yang baik. Apabila dalam pembelajaran IPS tidak diimbangi dengan sikap sosial yang baik dapat menyebabkan kesenjangan sosial dan mempegaruhi etika siswa. Karena sesungguhnya etikalah yang merupakan hal pertama dan utama yang perlu diberikan dan ditindaklanjuti dalam pengelolaan pendidikan (Km et al., 2020).

Berdasarkan hasil observasi dan wawancara yang telah dilakukan di SD, khususnya pada mata pelajaran IPS, dikatakan bahwa dalam proses pembelajaran yang dilakukan telah menerapkan kurikulum 2013. Namun penerapan model pembelajaran yang mengacu pada kurikulum 2013 belum terlaksanakan secara maksimal. Hal tersebut dikarenakan masih ada siswa yang belum memahami materi pelajaran. Selain itu, saat di berikan kesempatan dalam mengemukakan pendapat selama proses pembelajaran beberapa siswa kurang mempunyai 
etika dalam menghargai orang lain. Hal ini dikarenakan setiap siswa memiliki perbedaan baik dari pendapat maupun latarbelakang serta kurangnya interaksi dalam pembelajaran terhadap satu sama lain. Permasalahan tersebut hampir serupa dengan penelitian yang dilakukan oleh (Rosidah, 2016) yang menyatakan bahwa pelajaran IPS masih terpusat pada guru dan siswa cenderung pasif, situasi belajar mengajar yang kurang kondusif dan banyak siswa yang ramai sendiri, mengganggu teman, sekadar corat-coret buku, melamun bahkan adapula yang mengantuk. Dalam komunikasi verbal sudah tampil kata-kata jorok, yang sudah barang tentu tidak diasosiasi dengan orang terpelajar. Sesama teman suka tidak peduli, mudah emosi, dll (TAS'ADI, 2016).

Permasalahan tersebut perlu adanya tindakan untuk menghubungkan pembelajaran pada mata pelajaran IPS agar lebih mudah dipahami dan siswa memiliki etika yang baik. Tindakan ini merupakan tantangan bagi guru untuk memilih model pembelajaran yang dapat memotivasi siswa, materi yang dipelajari dapat diingat lebih lama serta bermakna. Pembelajaran pada mata pelajaran IPS semestinya disajikan dengan membuat siswa mampu memahami materi pelajaran serta saling menghargai satu sama lain selama belajar tanpa memandang individu secara fisik maupun non fisik untuk bukti nyata dalam belajar tentang kehidupan sosial yang baik. Dengan adanya penanaman etika yang baik dalam pembelajaran, siswa dapat belajar saling menghargai perbedaan yang ditemuinya dan senantiasa dapat berjasama dalam menerima pendapat sehingga pembelajaran menjadi lebih harmonis, dan mampu meningkatkan kompetensi pengetahuan IPS siswa. Model pembelajaran yang demikian dapat diimplementasikan melalui model discovery learning berbasis kearifan lokal catur paramitha, dengan menggunakan model ini siswa dituntut untuk secara aktif belajar menemukan sendiri berbagai konsep dan prinsip melalui ajaran susila atau etika yang baik. Maka dari itu, model pembelajaran discovery learning berbasis kearifan lokal catur paramitha dapat membuat siswa lebih mudah memahami suatu materi/permasalahan, serta menanamkan bagaimana beretika yang baik melalui ajaran saling menghargai dan menyayangi tanpa memandang perbedaan setiap individu. Hal ini diperkuat dengan penelitian yang dilakukan oleh Arindah (2015) yang menyatakan bahwa perlakuan menggunakan model discovery learning memberikan pengaruh yang baik terhadap hasil belajar siswa, hal ini dikarenakan model pembelajaran discovery learning dapat memberikan pengalaman belajar yang dieroleh oleh siswa.

Model Discovery Learning mengajarkan anak untuk aktif menemukan sendiri konsep materi atau mencari informasi sendiri tanpa diberi tahu oleh pengajar terlebih dahulu mengenai materinya sehingga apa yang telah ditemukan sendiri oleh anak akan lebih tahan lama dalam ingatan (Rahayu et al., 2019). Pendapat tersebut sejalan dengan (Anugraheni et al., 2018) yang menyatakan bahwa discovery learning merupakan model pembelajaran yang melatihkan pada siswa belajar mandiri untuk meningkatkan keterampilan dan proses kognitif. Menurut Kurniasih \& Sani dalam (Fitriyah et al., 2017) discovery learning dijabarkan sebagai siswa mengorganisasikan sendiri materi pelajaran yang tidak diberikan seutuhnya. (Edeltrudis, 2018) menjelaskan bahwa saat pembelajaran discovery, siswa diberikan kesempatan menjadi seorang problem solver, maka siswa secara bebas dapat menemukan pengetahuannya sendiri. Melalui model discovery learning, siswa secara aktif menyelidiki hubungan, mengumpulkan materi, dan digunakan dalam menemukan konsep atau prinsip pada suatu peristiwa tersebut (Kodir, 2018). Model discovery learning mengacu kepada teori belajar yang didefinisikan sebagai proses pembelajaran yang terjadi bila pelajar tidak disajikan dengan pelajaran dalam bentuk finalnya, tetapi diharapkan peserta didik mengorganisasi sendiri (Anis, 2017). Kurniasih dalam (Noperman, 2013) menjelaskan kelebihan model iti antara lain yaitu (1) pembelajaran lebih berorientasi pada siswa, (2) menimbulkan rasa senang pada siswa kerena tumbuhnya rasa menyelidiki dan berhasil, (3) membantu siswa dalam menghilangkan keraguan karena mengarah kepada kebenaran yang 
final dan pasti. Pada penelitian yang dilakukan oleh (Winoto \& Prasetyo, 2020) menyebutkan kelebihan model pembelajaran discovery learning adalah pengetahuan yang diperoleh melalui metode ini sangat pribadi dan ampuh karena menguatkan pengertian, ingatan dan transfer. Kemudian Kurniasih \& Sani dalam (Rahayu et al., 2019) telah menyebutkan langkah-langkah dalam menerapan model discovery learning, yaitu: 1) stimulasi/pemberian rangsang, 2) pernyataan/identifikasi masalah, 3) pengumpulan data, 4) pengolahan data serta, 5) pembuktian,6) menarik kesimpulan.

Dikarenakan akan banyak menemukan pendapat dan latar belakang yang berbeda dalam kelas, maka pengalaman belajar berasaskan ajaran etika melalui basis kearifan lokal catur paramitha akan sangat baik diberikan kepada siswa. Pada Istilah kearifan lokal sangat erat hubungannya dengan budaya sekitar. Kearifan lokal adalah satu kesatuan dari kebudayaan yang bersifat fungsional dan telah mentradisi secara berkelanjutan (Aditya et al., 2019). Perpaduan nilai kearifan lokal dalam proses pembelajaran memberikan pembelajaran yang bermuatan pendidikan etika yang baik sehingga pengetahuan yang diperoleh dapat lebih bermakna dan berdampak positif. Sedangkan menurut Pada ajaran Agama Hindu kata catur paramitha terdiri terdiri dari dua suku kata yakni kata Catur artinya empat (4) dan Paramitha berarti perbuatan yang baik. Jadi Catur paramitha artinya empat macam perbuatan baik dan mulia (Suhardana, 2015). Meskipun Catur paramitha dalam ajaran umat beragama Hindu, tidak ada salahnya juga dibelajarkan pada umat lainnya. Karena selain melestarikan kearifan lokal yang ada di Bali, tetapi juga dapat mengajak umat lain dalam cakupan ini adalah siswa non hindu untuk dapat sama-sama belajar tentang beretika yang baik dan menghargai orang lain (Km et al., 2020). Konsep Catur paramitha ini bisa dijadikan modal bagi anak untuk bersosialisasi dengan individu lainnya serta merangsang tumbuhnya jiwa individualisme dan cenderung menurunkan rasa persahabatan, cinta kasih dan toleransi (Wisnu Budi Wijaya, 2019). Adapun bagian-bagian dari Catur paramitha yaitu, pada bagian pertama adalah Maitri yang artinya teman atau sahabat. Bagian kedua yaitu Karuna yang artinya welas asih atau cinta kasih. Bagian yang ketiga adalah Mudhita, yang artinya selalu gembira, senang, riang dan tidak pernah mempunyai sifat kotor seperti iri hati, dan dengki. Dan bagian yang keempat yaitu Upeksa, yang artinya toleransi. Dari penjelasan tersebut, proses pembelajaran menggunakan implementasi ajaran Catur paramitha dapat mengajak siswa untuk selalu beretika dan berbudi luhur yang baik, serta selalu menghargai setiap pendapat maupun perbedaan individu melalui empat ajaran perbuatan luhur.

Pembelajaran dengan menggunakan model discovery learning berbasis kearifan lokal catur paramitha melibatkan siswa untuk aktif menemukan sendiri pengetahuannya, dan melaksanakan pembelajaran menggunakan etika baik yang menumbuhkan rasa rendah hati, tidak sombong, serta memotivasi siswa untuk mau belajar dan bertanggung jawab. Yang diutamakan adalah bagaimana siswa tetap mampu memiliki etika dan karakter yang baik selama belajar dengan berlandaskan sifat serta sikap yang bersahabat, saling menyayangi, bersimpati, dan toleransi sesuai dengan landasan kearifan lokal di Bali mengenai perbuatan luhur dalam melakukan kegiatan sehari-hari agama hindu yaitu catur paramitha.

\section{Metode}

Penelitian ini dirancang sesuai prosedur penelitian eksperimen semu dengan rancangan non-equivalent control group desain. Analisis data penelitian ini menggunakan separated varians. Variabel bebas yang digunakan adalah model discovery learning berbasis kearifan lokal catur paramitha, dan variabel terikat yang digunakan adalah kompetensi pengetahuan IPS. Langkah-langkah yang ditempuh dalam penelitian ini yaitu terlebih dahulu dilakukan wawancara dengan kepala gugus, kepala sekolah dan wali kelas lima pada masingmasing sekolah di SD Negeri Gugus Ir Soekarno Kecamatan Denpasar Selatan, menentukan sampel, menyusun perangkat dan intrumen, mengkonsultasikan dengan guru kelas dan dosen 
pembimbing sekaligus sebagai dosen ahli, melaksanakan uji coba, memberikan pre test, menentukan undian untuk kelompok eskperimen dan kelompok kontrol, melaksanakan proses pembelajaran sebanyak 6 kali pertemuan, memberikan post test kepada kedua kelompok, dan menganalisis data hasil penelitian.

Populasi penelitian adalah keseluruhan kelompok yang terdiri atas objek atau subjek dari mana sampel-sampel akan diambil untuk dijadikan sumber data dalam penelitian (Dr. Desak Putu Parmiti, 2017). Populasi dalam penelitian ini adalah seluruh SD Negeri Gugus Ir Soekarno Kecamatan Denpasar Selatan yang berjumlah 259 orang. Dari populasi tersebut, diambil 2 sampel untuk dijadikan sumber data penelitian. Teknik yang digunakan dalam menentukan sampel penelitian ini yaitu teknik cluster random sampling. Pemilihan sampel penelitian ini tidak dilakukannya pengacakan individu melainkan hanya pengacakan kelas. Dalam penelitian ini pengambilan sampel dipilih dengan cara undian. Setelah mendapatkan 2 kelas tersebut, diberikan pretest. Menurut Sugiyono dalam (Nita Noviani, 2013) pretest diberi sebelum perlakuan. Dengan demikian hasil perlakuan dapat diketahui lebih akurat, karena dapat dibandingkan dengan keadaan sebelum diberi perlakuan. Skor dari hasil pre test digunakan untuk penyetaraan kelas-kelas dalam sampel. Skor dari hasil pre test kemudian dianalisi dengan uji t. Data hasil pre test diujikan terlebih dahulu dengan uji prasyarat antara lain uji normalitas dan homogenitas, sebelum menganalisis menggunakan uji t. Dari kedua kelompok sampel tersebut pengundian dilakukan lagi dan didapatkan SD Negeri 2 Pedungan yang ditetapkan sebagai kelompok eksperimen yang berjumlah 34 orang dan SD Negeri 5 Pedungan yang ditetapkan sebagai kelompok kontrol yang berjumlah 34 orang. Pada kelompok eksperimen diberi perlakuan model discovery learning berbasis kearifan lokal catur paramitha dan kelompok kontrol diberi pembelajaran konvensional.

Pada penelitian ini menggunakan metode pengumpulan data berupa tes. Tes merupakan cara digunakan untuk menilai prestasi seseorang yang berupa tugas yang harus dikerjakan (Hadi \& Manurung, 2019). Tes objektif dengan bentuk pilihan ganda biasa yang dengan 4 pilihan ( $a, b, c$, atau d). Instrumen yang digunakan digunakan sebagai pengumpulan data terebih dahulu diuji coba. Uji coba yang dilakukan untuk menentukan validitas, daya beda soal, tingkat kesukaran, dan reliabilitas dengan melibatkan responden sebanyak 38 orang siswa. Validitas butir soal diukur dalam bentuk bentuk objek pilihan ganda biasa menggunakan rumus koefisien korelasi point biseral $\left(r_{\mathrm{pbi}}\right)$ dengan $\mathrm{r}_{\text {tabel }}$ pada taraf signifikansi $5 \%$. Berdasarkan hasil analisis diketahui dari 40 butir soal yang diujikan diperoleh hasil 32 butir soal dinyatakan valid dan 8 butir soal dinyatakan tidak valid. Untuk menentukan daya beda dan indek kesukaran tes yang dibuat maka terlebih dahulu menentukan kelompok atas dan kelompok bawah. Berdasarkan hasil analisis dari 32 butir soal, diperoleh 2 butir soal yang berkualifikasi sangat baik, 12 butir soal yang berkualifikasi baik, 16 butir soal yang berkualifikasi cukup, dan 2 butir soal yang berkualifikasi jelek. Butir tes dengan kategori jelek tidak dipergunakan agar hasil tes yang berkualitas. Sedangkan tingkat kesukaran menunjukkan 6 butir yang berkriteria sukar, 20 butir yang berkriteria sedang dan 6 berkriteria mudah. Berdasarkan hasil analisis pada penelitian, maka diketahui sebanyak 30 butir tes yang dapat dipergunakan sebagai instrumen penelitian. Penelitian ini menggunakan teknik analisis data berupa analisis statistik inferensial. Analisis data gain skor digunakan untuk menormaliasasikan hasil data pre test dan post test. Hasil analisi data gain skor ternormalisasi dideskripsikan dengan mengonversikan ke dalam penilain acuan norma (PAN) dengan skal 5 (lima). Teknik analisis data yang dilakukan untuk uji hipotesis menggunakan uji t. Uji t dilakukan setelah memenuhi uji prasyarat yaitu uji normalitas sebaran data dan uji homogentitas. Uji normalitas data dapat diketahui dengan menggunakan rumus Kolmogorov Smirnov dan uji homogenitas varians dengan menggunakan rumus uji F. Sesuai dengan hipotesis alternatif ( $\mathrm{Ha}$ ) yang telah diajukan, maka dapat dirumuskan hipotesis nol (Ho) yang berbunyi tidak dapat perbedaan Model Discovery Learning Berbasis Kearifan Lokal Catur 
paramitha Terhadap Kompetensi Pengetahuan IPS Siswa Kelas V SD Negeri Gugus Ir Soekarno Kecamatan Denpasar Selatan.

\section{Hasil dan Pembahasan}

Data hasil kompetensi pengetahuan IPS didapatkan dari gain skor yang ternormalisasikan dengan menganalisis data pre test dan post test kedua kelompok. Pada penelitian ini, data yang diperoleh dibagi menjadi 2 yaitu data kompetensi pengetahuan IPS kelompok eksperimen dan data kompetensi pengetahuan kelompok kontrol. Data gain skor ternormalisasi kompetensi pengetahuan IPS kelompok eksperimen di peroleh rata-rata sebesar 0,517, standar deviasi sebesar 0,185, varians sebasar 0,034, nilai gain skor ternormalisasi minimum sebesar 0,003 , dan nilai gain skor ternormalisasi maksimum sebesar 0,125. Perhitungan PAN skala 5 (lima) pada kelompok eksperimen berada pada predikat cukup. Sedangkan, data gain skor ternormalisasi kompetensi pengetahuan IPS kelompok kontrol di peroleh rata-rata sebesar 0,383, standar deviasi sebesar 0,174, varians sebasar 0,030, nilai gain skor ternormalisasi minimum sebesar 0,000, dan nilai gain skor ternormalisasi maksimum sebesar 0,058. Perhitungan PAN skala 5 (lima) pada kelompok eksperimen berada pada predikat cukup. Rekapitulasi perhitungan data penelitian dapat dilihat pada Tabel berikut.

Tabel 1. Deskripsi Data Gain Skor Ternormalisasi Kompetensi Pengetahuan IPS

\begin{tabular}{lcc}
\hline \multicolumn{1}{c}{ Statistika } & $\begin{array}{c}\text { Kelompok } \\
\text { Eksperimen }\end{array}$ & $\begin{array}{c}\text { Kelompok } \\
\text { Kontrol }\end{array}$ \\
\hline Rata-Rata & 0,517 & 0,383 \\
Standar Deviasi & 0,185 & 0,174 \\
Varians & 0,034 & 0,030 \\
Nilai Gain Skor Ternormalisasi Minimum & 0,003 & 0,000 \\
Nilai Gain Skor Ternormalisasi Maksimum & 0,125 & 0,058 \\
\hline
\end{tabular}

Selanjutnya, dilakukan uji prasyarat yaitu uji normalitas sebaran data dan uji homogenitas varians. Uji normalitas sebaran data kompetensi pengetahuan IPS berfungsi untuk mengetahui data yang diperoleh dari penelitian saat uji hipotesis berditribusi normal atau tidak. Berdasarkan hasil uji normalitas sebaran data kelompok eksperimen, diperoleh harga nilai maksimum $\left|F_{r}-F_{s}\right|=0,125$ dan harga tabel Kolmogorov-Smirnov untuk taraf signifikan $5 \%(\alpha=0,05)=0,227$ karena nilai harga nilai maksimum $\left|F_{r}-F_{s}\right| \leq$ harga tabel Kolmogorov-Smirnov maka sebaran data gain skor ternormalisasi berdistribusi normal. Sedangkan hasil uji normalitas sebaran data kelompok kontrol yaitu harga nilai maksimum $\left|F_{r}-F_{s}\right|=0,068$ dan harga Tabel Kolmogorov-Smirnov untuk taraf signifikan 5\% $(\alpha=$ $0,05)=0,227$ karena harga nilai maksimum $\left|F_{r}-F_{s}\right| \leq$ harga Tabel Kolmogorov-Smirnov maka sebaran data gain skor ternormalisasi berdistribusi normal.

Tabel 2. Hasil Uji Normalitas Kelompok Eksperimen dan Kelompok Kontrol

\begin{tabular}{llcccc}
\hline No & Kelompok Sampel & $\begin{array}{c}\text { Jumlah } \\
\text { Sampel }\end{array}$ & $\begin{array}{c}\text { Nilai } \\
\text { Maksimum } \\
\left|\boldsymbol{F}_{\boldsymbol{r}}-\boldsymbol{F}_{\boldsymbol{s}}\right|\end{array}$ & $\begin{array}{c}\text { harga tabel } \\
\text { Kolmogorov- } \\
\text { Smirnov }\end{array}$ & Kesimpulan \\
\hline 1 & Kelompok Eksperimen & 34 & 0,125 & 0,227 & Berdistribusi Normal \\
2 & Kelompok Kontrol & 34 & 0,058 & 0,227 & Berdistribusi Normal \\
\hline
\end{tabular}


Kemudian, uji homogenitas varians dilakukan berdasarkan data kompetensi pengetahuan IPS yang menggunakan data gain skor ternormalisasi kelompok eksperimen dan kelompok kontrol. Berdasarkan hasil perhitungan, diperoleh $F_{\text {hitung }}=1,128$. Sedangkan $F_{\text {tabel }}$ $=3,99$. Dengan taraf signifikan $5 \%(\alpha=0,05)$ dengan df $1=2-1=1$ dan df $268-2=66$. Maka nilai $\mathrm{F}_{\text {hitung }}=1,128<\mathrm{F}_{\text {tabel }}=3,99$, sehingga dapat dinyatakan data gain skor ternormalisasi kompetensi pengetahuan IPS memiliki varians yang homogen.

Tabel 3. Uji Homogenitas Varians Kelompok Eksperimen dan Kelompok Kontrol

\begin{tabular}{clcccccc}
\hline No & \multicolumn{1}{c}{ Sampel } & Varians & dk & df & $\mathbf{F}_{\text {hitung }}$ & $\mathbf{F}_{\text {tabel }}$ & Kesimpulan \\
\hline 1 & Kelompok Eksperimen & 0,034 & \multirow{2}{*}{66} & \multirow{2}{*}{1} & \multirow{2}{*}{1,128} & \multirow{2}{*}{3,99} & \multirow{2}{*}{ Homogen } \\
2 & Kelompok Kontrol & 0,030 & & & & & \\
\hline
\end{tabular}

Setelah mengetahui data kompetensi pengetahuan IPS berdistribusi normal dan homogen maka selanjutnya dianalisis menggunakan uji statistik berupa uji t dengan rumus separated varians. Berdasarkan hasil perhitungan hasil analisis uji t diperoleh 3,065 dan untuk taraf signifikan 5\% dengan $\mathrm{dk}=(34+34-2)=66$ diperoleh $\mathrm{t}_{\text {tabel }}=2,00$. Dengan kriteria $\mathrm{t}_{\text {hitung }}>\mathrm{t}_{\text {tabel }}$ yaitu $\mathrm{t}_{\text {hitung }}=3,065>\mathrm{t}_{\text {tabel }}=2,000$ maka, $\mathrm{H}_{\mathrm{o}}$ yang berbunyi tidak terdapat perbedaan model discovery learning berbasis kearifan lokal catur paramitha terhadap kompetensi pengetahuan IPS siswa kelas V Gugus Ir Soekarno Kecamatan Denpasar Selatan ditolak (gagal diterima). Berdasarkan hasil analisis diperoleh perbedaan yang signifikan kompetensi pengetahuan IPS siswa kelompok eksperimen yang dibelajarkan dengan model discovery learning berbasis kearifan lokal catur paramitha dan kelompok kontrol yang dibelajarkan dengan pembelajaran konvensional dengan kata lain variabel bebas yaitu model discovery learning berbasis kearifan lokal catur paramitha memiliki pengaruh terhadap variabel terikat yaitu kompetensi pengetahuan IPS siswa kelas V SD Negeri Gugus Ir Soekarno Kecamatan Denpasar Selatan.

Secara deskripstif, kompetensi pengetahuan IPS siswa kelompok eksperimen lebih tinggi dibandingkan dengan kelompok kontrol. Hal ini didasarkan dengan hasil rata-rata gain

skor ternormalisasi kelompok ekperimen $\bar{X}=0,517$. Kemudian di konservasikan pada tabel PAN skala 5 (lima), sehingga diketahui kompetensi pengetahuan IPS kelompok eksperimen pada predikat cukup. Sedangkan hasil rata-rata gain skor ternormalisasi kelompok kontrol

adalah $\bar{X}=0,383$. Kemudian di konservasikan pada tabel PAN skala 5 (lima), sehingga diketahui kompetensi pengetahuan IPS kelompok kontrol pada predikat cukup. Berdasarkan hasil uji hipotesis diperoleh $t_{\text {hitung }}=3,065$ sedangkan pada taraf signifikansi $5 \%$ dan dk $=66$ diperoleh nilai $t_{\text {tabel }}=2,000$ sehingga $t_{\text {hitung }}=3,065>t_{\text {tabel }}=2,000$. Dengan demikian, hipotesis nol $\left(\mathrm{H}_{0}\right)$ ditolak. Hal ini berarti terdapat perbedaan yang signifikan kompetensi pengetahuan IPS antara kelompok siswa yang dibelajarkan melalui model discovery learning berbasis kearifan lokal catur paramitha dan kelompok siswa yang dibelajarkan melalui pembelajaran konvensional pada siswa kelas V SD Negeri Gugus Ir. Soekarno Kecamatan Denpasar Selatan. Hasil analisis uji t pada sampel penelitian ini disajikan sebagai berikut.

Tabel 4. Rekapitulasi Hasil Uji t Kelompok Sampel Penelitian

\begin{tabular}{clccccc}
\hline No & $\begin{array}{c}\text { Kelompok } \\
\text { Sampel }\end{array}$ & $\mathbf{N}$ & Dk & $\mathbf{t}_{\text {hitung }}$ & $\mathbf{t}_{\text {tabel }}$ & Simpulan \\
\hline 1 & Eksperimen & 34 & 66 & 3,065 & 2,000 & $\mathrm{H}_{\mathrm{o}}$ ditolak \\
2 & Kontrol & 34 & & & \\
\hline
\end{tabular}


Dari hasil pengamatan pada kelompok eksperimen, pembelajaran dengan menggunakan model discovery learning berbasis kearifan lokal catur paramitha kelompok eksperimen berlangsung dengan siswa lebih bersemangat saat berdiskusi kelompok, siswa lebih aktif dalam memecahkan permasalahan yang diberikan guru, karena saat berkelompok lebih banyak bertukar pendapat, siswa dapat menghargai dan mengormati perbedaan saat berdiskusi, serta saat diberikan tes, siswa lebih lama mengingat materi pelajaran. Sedangkan pada kelompok kontrol, pembelajaran konvensional lebih banyak menggunakan metode ceramah, tanya jawab serta penugasan berjalan kurang optimal. Guru hanya menjelaskan materi secara singkat kemudian siswa diberikan tugas yang terdapat pada buku pelajaran, sehingga siswa cenderung pasif saat pembelajaran. Pada saat penilaian pembelajaran hanya menilai dari hasil akhir tesnya saja tanpa memperdulikan proses yang dilalui dalam pembelajaran. Dalam kegiatan pembelajaran pada kelompok kontrol yang menggunakan pembelajaran konvensional, siswa menjadi sangat tergantung dengan informasi guru, siswa tidak terlalu berpartisipasi dalam pembelajaran, siswa hanya membahas materi yang terdapat pada buku saja, dan siswa kurang bersemangat dalam belajar.

Hasil temuan pada penelitian ini mendukung hasil penelitian sebelumnya yang disampaikan oleh (Kristin, 2016) dengan menyatakan bahwa penerapan model discovery learning berpengaruh terhadap hasil belajar IPS siswa. Penelitian ini diperkuat oleh (Drs. Ida Bagus Surya Manuaba, 2017) yang mengatakan bahwa terdapat pengaruh model discovery learning berbantuan media audio visual terhadap kompetensi pengetahuan IPS siswa kelas IV SD Gugus Letda Made Putra Tahun Pelajaran 2016/2017. Dan penelitian yang dilakukan oleh (DB.KT.NGR. Semara Putra \& Drs. I Wayan Sujana, 2017) juga mendukung penelitian ini yang menyatakan bahwa terdapat perbedaan nilai rerata hasil belajar IPS yang lebih tinggi antara siswa yang mengikuti pembelajaran menggunakan model discovery learning berbantuan LKS dan siswa yang mengikuti pembelajaran konvensional yakni, ( $X=79,23$ > $X=77,12$ ), hal ini berarti terdapat pengaruh model discovery learning berbantuan LKS terhadap hasil belajar IPS. Melalui penjelasan tersebut, model pembelajaran discovery learning berbasis kearifan lokal catur paramitha dapat direkomendasikan dalam pembelajaran siswa.

\section{Simpulan}

Berdasarkan hasil penelitian dan pembahasan diperoleh perbedaan yang signifikan kompetensi pengetahuan IPS siswa kelompok eksperimen yang dibelajarkan dengan model discovery learning berbasis kearifan lokal catur paramitha dan kelompok kontrol yang dibelajarkan dengan pembelajaran konvensional dengan kata lain variabel bebas yaitu model discovery learning berbasis kearifan lokal catur paramitha memiliki pengaruh terhadap variabel terikat yaitu kompetensi pengetahuan IPS siswa kelas V SD Negeri Gugus Ir Soekarno Kecamatan Denpasar Selatan. Sebagai tindak lanjut dari hasil penelitian, maka penelitian ini disarankan kepada (1) Kepala sekolah sebaiknya menyediakan fasilitas pembelajaran yang lengkap agar siswa dapat menfaatkan fasilitas tersebut dan guru dapat membelajarkan siswa dengan model-model pembelajaran inovatif guru sehingga siswa dapat termotivasi untuk belajar serta kepala sekolah dapat memajukan mutu sekolah melalui hasil belajar siswa. (2) Guru hendaknya lebih inventif memfasilitasi siswa dalam pembelajaran berupa sumber belajar dengan menggunakan model pembelajaran discovery learning berbasis kearifan lokal catur paramitha sehingga tercipta pembelajaran yang aktif baik secara mental maupun emosional serta materi yang dipelajari akan lebih lama melekat dalam diri siswa. (3) Pada hasil penelitian ini dapat disarankan kepada peneliti lain sebagai kajian penelitian relevan untuk penunjang penelitian selanjutnya khususnya pada kompetensi pengetahuan IPS maupun pelajaran lain untuk memperoleh hasil yang baik. 


\section{Daftar Pustaka}

Aditya, I. K. D., Sumantri, M., \& Astawan, I. G. (2019). Pengaruh Model Pembelajaran Learning Cycle (5e) Berbasis Kearifan Lokal Terhadap Sikap Disiplin Belajar Dan Hasil Belajar Ipa Siswa Kelas Iv Sd Gugus V Kecamatan Sukasada. Jurnal Pendidikan Multikultural Indonesia. https://doi.org/10.23887/jpmu.v2i1.20792

Anis, Y. W. (2017). Peningkatan Kemandirian dan Hasil Belajar Ips Menggunakan Model Discovery Learning Di Kelas Viii Smp. Jurnal EDUCATIO: Jurnal Pendidikan Indonesia, 3(2), 15. https://doi.org/10.29210/12017293

Anugraheni, A. D., Oetomo, D., \& Santosa, S. (2018). Pengaruh Model Discovery Learning dengan Pendekatan Contextual Teaching Learning terhadap Keterampilan Argumentasi Tertulis Ditinjau dari Kemampuan Akademik Siswa SMAN Karangpandan The Effect of Discovery Learning Model with Contextual Teaching Learning A. Bioedukasi, 11, 123-128.

Arindah, A. (2015). Pengaruh Penerapan Model Discovery Learning Terhadap Hasil Belajar Siswa Pada Mata Pelajaran Ips Kelas Iv Sd. Jurnal Penelitian Pendidikan Guru Sekolah Dasar, 3(2), 254169.

DB.KT.NGR. Semara Putra, S., \& Drs. I Wayan Sujana, S. (2017). Pengaruh Model Discovery Learning Berbantuan Lks Terhadap Hasil Belajar Ips Siswa Kelas V. MIMBAR PGSD Undiksha, 5(2), 1-9. https://doi.org/10.23887/jjpgsd.v5i2.11076

Dr. Desak Putu Parmiti, M. . (2017). Pengaruh Model Pembelajaran Discovery Learning Berbasis Lingkungan Terhadap Hasil Belajar Ipa Pada Siswa Kelas V Semester Genap Tahun Pelajaran 2016/2017 Di Sd Gugus Ii Kecamatan Tampaksiring. MIMBAR PGSD Undiksha, 5(2). https://doi.org/10.23887/jjpgsd.v5i2.10712

Drs. I Wayan Sujana, S. (2017). Pengaruh Model Discovery Learning Terhadap Kompetensi Pengetahuan Ipa Siswa Kelas Vi Sd Gugus Yos Sudarso Kecamatan Denpasar Selatan Tahun Pelajaran 2016/2017. MIMBAR PGSD Undiksha, 5(2). https://doi.org/10.23887/jjpgsd.v5i2.10655

Drs. Ida Bagus Surya Manuaba, S. (2017). Pengaruh Model Problem Based Learning Berbantuan Media Audio Visual Terhadap Penguasaan Kompetensi Ips. MIMBAR PGSD Undiksha, 5(2), 1-8. https://doi.org/10.23887/jjpgsd.v5i2.11000

Edeltrudis, M. (2018). Penggunaan Model Pembelajaran Discovery Learning Untuk Meningkatkan Prestasi Belajar Peserta Didik Pada Kompetensi Dinamika LitosfeR. Jurnal Imiah Pendidikan Dan Pembelajaran. https://doi.org/10.23887/jipp.v2i3.16312

Fitriyah, F., Murtadlo, A., \& Warti, R. (2017). Pengaruh Model Pembelajaran Discovery Learning terhadap Hasil Belajar Matematika Siswa MAN Model Kota Jambi. Jurnal Pelangi, 9(2), 108-112. https://doi.org/10.22202/jp.2017.v9i2.1898

Hadi, K., \& Manurung, B. (2019). Analisis Daya Beda Soal Tes Berpikir Tingkat Tinggi. 6(2), 85-91.

Herijanto, B. (2012). Journal of Educational Social Studies Pengembangan Cd Interaktif Pembelajaran Ips Materi Bencana Alam. In JESS.

Km, N., Wardani, T., \& Wiyasa, I. K. N. (2020). Pengaruh Model Pembelajaran Kooperatif Tipe Jigsaw Berbasis Catur paramitha Terhadap Kompetensi Pengetahuan Matematika. 3(1), 25-34.

Kodir, Abdul. Menejemen Pembelajaran Saintifik Kurikulum 2013 Pembelajaran yang berpusat pada Siswa. Bandung : Pustaka Setia 
Implementasi Nilai-Nilai Kearifan Lokal Catur Paramitha dalam Pembelajaran dengan Model Discovery Learning Berpengaruh Positif Terhadap Kompetensi Pengetahuan IPS

Kristin, F. (2016). Analisis model pembelajaran discovery learning dalam meningkatkan hasil belajar siswa SD. Jurnal Pendidikan Dasar PerKhasa.

Kristin, F. (2018). Meta-Analisis Pengaruh Model Pembelajaran Role Playing Terhadap Hasil Belajar Ips. Refleksi Edukatika: Jurnal Ilmiah Kependidikan. https://doi.org/10.24176/re.v8i2.2356

Meldina, T., Agustin, A., \& Harahap, S. H. (2020). Integrasi Pembelajaran IPS pada Kurikulum 2013 di Sekolah Dasar Institut Agama Islam Negeri Curup Sekolah Dasar Negeri 10 Pasaman PENDAHULUAN Pendidikan semestinya sudah dilakukan sedari dini yaitu dengan melakukan pendidikan dasar . Pada Undang-undang No. 4(1).

Nita Noviani. (2013). Pengaruh Model Pembelajaran Discovery Learning terhadap Motivasi Belajar Ips Siswa. Journal of Chemical Information and Modeling, 53(9), 1689-1699. https://doi.org/10.1017/CBO9781107415324.004

Noperman, F. (2013). Jurnal PGSD. 1(1), 10.

Putra, I. G. D. (2020). Hasil belajar IPS menggunakan Kolaborasi Model Discovery Learning Berbasis Media Animasi. 4, 103-109.

Rahayu, I. P., Christian Relmasira, S., \& Asri Hardini, A. T. (2019). Penerapan Model Discovery Learning untuk Meningkatkan Keaktifan dan Hasil Belajar Tematik. Journal of Education Action Research, 3(3), 193. https://doi.org/10.23887/jear.v3i3.17369

Rahmad. (2016). Kedudukan Ilmu Pengetahuan Sosial ( IPS ) pada Sekolah Dasar. Muallimuna: Jurnal Madrasah Ibtidaiyah.

Rahmayani, A., Siswanto, J., \& Arief Budiman, M. (2019). Pengaruh Model Pembelajaran Discovery Learning dengan Menggunakan Mediavideo Terhadap Hasil Belajar. Jurnal Ilmiah Sekolah Dasar. https://doi.org/10.23887/jisd.v3i2.18055

Rosidah, A. (2016). Penerapan Media Pembelajaran Visual Untuk Meningkatkan Pemahaman Konsep Siswa Pada Mata Pelajaran Ips. Jurnal Cakrawala Pendas, 2(2). https://doi.org/10.31949/jcp.v2i2.499

Sudhita, Romi. 2019. Istilah Istilah Kependidikan. Singaraja: Mahima Institut Indonesia

Suhardana, K.M. 2015. Catur dan Sad Paramitha Jalan Menuju Keluhuran Budi. Denpasar: Paramita.

TAS'ADI, R. (2016). Pentingnya Etika Dalam Pendidikan. Ta'dib, 17(2), 189. https://doi.org/10.31958/jt.v17i2.272

Widani, N. K. T., Sudana, D. N., \& Agustiana, I. G. A. T. (2019). Pengaruh Model Pembelajaran Inkuiri Terbimbing Terhadap Hasil Belajar Ipa Dan Sikap Ilmiah Pada Siswa Kelas V Sd Gugus I Kecamatan Nusa Penida. Journal of Education Technology. https://doi.org/10.23887/jet.v3i1.17959

Winoto, Y. C., \& Prasetyo, T. (2020). Efektivitas Model Problem Based Learning Dan Discovery Learning Terhadap Kemampuan Berpikir Kritis Siswa Sekolah Dasar. Jurnal Basicedu, 4(2), 228-238. https://doi.org/10.31004/basicedu.v4i2.348

Wisnu Budi Wijaya, I. K. (2019). Menanamkan Konsep Catur Paramita Pada Anak Usia Dini Di Lingkungan Keluarga Dan Sekolah. Pratama Widya: Jurnal Pendidikan Anak Usia Dini, 3(2), 41-46. https://doi.org/10.25078/pw.v3i2.737 